\title{
Assessment of Fluoride and Nitrate in Ground Water: Selected Villages of Mahabubnagar Mandal \& District, Telangana State (India)
}

\author{
Dasaiah Srinivasulu ${ }^{1}$, GRK Naidu² \\ ${ }^{a}$ Research Scholar, Department of Environmental Sciences, Sri Venkateswara University, Tirupati-517 502 Andhra Pradesh, India \\ ${ }^{\mathrm{b}}$ Emeritus Professor, Department of Environmental Sciences, Sri Venkateswara University, Tirupati-517 502 Andhra Pradesh, India
}

\begin{abstract}
An attempt was made to assess the fluoride and nitrate concentration in ground water of selected villages of Mahabubnagar mandal and district where the ground water is main source for drinking. Ground water samples were collected from different bore wells of villages and analysed some important parameters such as temperature, colour, odour, pH, Electrical conductivity, nitrate and fluoride. Findings reveal that all the ground water samples consists more than 1.0mg/lit. of fluoride and values of ground water samples ranges from 1.12mg/lit. to $1.91 \mathrm{mg} /$ lit. Highest value found Zamisthapur station i.e $1.91 \mathrm{mg} / \mathrm{lit}$. As per the maximum permissible limit for fluoride in drinking water 1.5mg/lit. prescribed by World Health Organisation (2004) and Bureau of Indian Standards(2009), 53\% of ground water samples in study area found beyond maximum permissible limits. Due to higher fluoride concentration present in ground water sources, few characteristics of fluorosis have been observed at alarming stage in the study area. Whereas Nitrates are concerned in two stations i.e Alipur(132mg/lit) and Machenpally $(109 \mathrm{mg} / \mathrm{lit}$.$) are found excess in limits. Remaining all samples found within the$ limits as prescribed by WHO.
\end{abstract}

Keywords: Ground water, fluoride, physico chemical parameters, permissible limit, and nitrates

\section{Introduction}

Water is most vital liquid for maintaining the life on the earth. About $97 \%$ water is exists in oceans that is not suitable for drinking and only $3 \%$ is fresh water wherein $2.97 \%$ is comprised by glaciers and ice caps and remaining little portion of $0.03 \%$ is available as a surface and ground water for human use (Miller, 1997). Safe drinking water is a basic need for good health and it is also a basic right of humans. Fresh water is already a limiting resource in many parts of the world. In the next century, it will become even more limiting due to increased population, urbanization and climate change (Jackson et al., 2001). Unfortunately, in developing countries like India, the drinking quality of water is continuously being contaminated and hazardous for human use due to high growth of population, expansion in industries, throwing away of waste water and chemical effluents into canals and other water sources. According to recent estimates, the quantity of available water in developing regions of South Asia, Middle East and Africa is decreasing sharply while quality of water is deteriorating rapidly due to fast urbanization, industrialisation, deforestation, land degradation etc.

Groundwater is the major source of drinking water and dietary fluoride in human beings in rural as well as urban areas throughout the world.

Fluoride ion in drinking water is known for both beneficial and detrimental effects on health. It is essential for normal mineralization of bones and formation of dental enamel with presence in small quantity (Chouhan and Flora, 2010). When fluoride is taken up more than the permissible limit, it becomes toxic and causes clinical and metabolic disturbances in animals and human beings such as dental and skeletal fluorosis (Singh et al., 2007). The amount of fluoride present naturally in groundwater is governed principally by climate, composition of the host rock and hydrogeology (Gupta et al.,2006). Some anthropogenic activities are also contributed to cause an increase in fluoride concentration in groundwater such as use of phosphatic fertilizers, pesticides, sewage, sludge and depletion of groundwater table etc., (Ramanaiah et al. 2006). Hence to monitor the groundwater quality a lot of studies carried out through-out the world now a days (Nagarajan et al. 2010; Gautam et al. 2011 and Kumar, 2011). Fluoride is considered as a major pollutant of ground water on global scale. Nearly 25 countries in the world are suffering from excess of fluoride content in the groundwater and India is one of them. Periodic incidences of high fluoride content in ground water have been reported in various states of India. Approximately 20 states of India are facing the problem of excessive fluoride in the ground water and about 62 million people including 6 million children suffering from fluorosis because of consumption of water with high fluoride concentrations (UNICEF, 1999). According to WHO (1997) the permissible limit for fluoride in drinking water is 1.5 $\mathrm{mg} / \mathrm{l}$, whereas, USPHS (1962) has set a range of allowable concentrations for fluoride in drinking water for a region depending on its climatic conditions because the amount of water consumed and consequently the amount of fluoride ingested being influenced primarily by the air temperature (Singh et al., 2007). The major sources of fluoride in groundwater are fluoride-bearing rocks such as fluorspar, cryolite, fluorapatite and hydroxylapatite (Agarwal et al., 1997). Fluoride ions from these minerals leaching into the groundwater and contribute to high fluoride concentrations (Latha et al., 1999; Ramesam and Rajagopalan 1985). 


\section{International Journal of Science and Research (IJSR) ISSN (Online): 2319-7064}

Index Copernicus Value (2013): 6.14 | Impact Factor (2014): 5.611

\subsection{Study Area}

Mahabubnagar, also known as Palamoor is a city in Mahabubnagar district of the Indian state of Telangana. It is a municipality and the headquarters of Mahabubnagar mandal in Mahabubnagar revenue division. It is located at $16.73^{\circ} \mathrm{N} 77.98^{\circ} \mathrm{E}$. It has an average elevation of 498 metres (1633 feet). The city of Mahabubnagar is located at a distance of $98 \mathrm{~km}$ from Hyderabad $108 \mathrm{~km}$ from Kurnool and $109 \mathrm{~km}$ from Raichur.

\subsection{Physiography}

Physiographically, major part of the district is a pediplain, punctuated by numerous small hills and valleys, inselbergs and rocks knobs. The southern part of the district stretching all along the northern bank of Krishna River between Manyapadu and Dindi River comprises upland region of variable altitude and forms the northern fringe of the South Central Upland of the slate, Plateau landforms also occur in northwestern part of the district in Korangal and shadnagar taluqs. The Krishna, the Tungabhadra, Peddavagu and Dindi Rivers are the important rivers in the district, Peddavagu River drains the westrn part of the district and the Dindi River and its tributaries drain the eastern part and both of them flow in the sourthernly direction. The district receives about 50-65 cm of annual rainfall and experiences semi arid climate. Black cotton, red sandy and calcareous loamy are the soil types in the district. The northern half of the district, especially the area south of Tungabhadra River, is covered by a thick blanket of black cotton soil.

\section{Materials \& Methods}

The sampling places are referred as stations and coded as S1 to S15. The stations are represented as Ramreddy gudem (S1), Bokkalonipally(S2), Zamisthapur(S3), Telugu gudem(S4), Oblaipally(S5), Machenpally(S6), Nehru Nagar(S7), Ramchandra puram(S8), Chowder pally(S9), Appai pally(S10), Narsapur(S11) Dharmapur(S12), Alipur(S13), Kodur(S14) and Oblaipally Thanda(S15) which are comes under Mahabubnagar mandal. Water sample collected from various bore wells of respective villages. The samples collected in $1000 \mathrm{ml}$ plastic bottles which were previously washed drenched overnight with $5 \%$ of $\mathrm{HNO}_{3}$ solution to avoid contamination. During sampling extra care was taken and plastic bottles were rinsed several times with the water being collected. All the samples were found odourless, colourless and temperature between $25^{\circ} \mathrm{C}-30^{\circ} \mathrm{C}$.

The $\mathrm{pH}$ of samples was determined by using a $\mathrm{pH}$ meter based on Wheatstone bridge principle. The electrical conductivity (EC) of the water samples was estimated by using Conductivity Meter. Fluoride in water samples was determined by SPANDS- zirconyl oxychloride method using UV-VIS spectrophotometer. The absorbance values obtained at $\lambda$ max equal to $570 \mathrm{~nm}$ were compared with the standard calibration curve for fluoride concentration. Nitrate also determined by spectrophotometer. All the experiments were carried out in triplicate and mean value of each sample was considered as the final reading.

\section{Results \& Discussions}

Table 1: Laboratory analysis of ground water samples

\begin{tabular}{|c|c|c|c|c|c|}
\hline $\begin{array}{c}\text { Name of the } \\
\text { Village }\end{array}$ & $\begin{array}{c}\text { Sampling } \\
\text { Station } \\
\text { code }\end{array}$ & $\mathrm{pH}$ & $\begin{array}{c}\mathrm{EC} \\
(\mu \mathrm{S} / \mathrm{cm})\end{array}$ & $\begin{array}{c}\mathrm{F} \\
(\mathrm{mg} / \mathrm{lit} .)\end{array}$ & $\begin{array}{c}\mathrm{NO}_{3} \\
(\mathrm{mg} / \mathrm{lit} .)\end{array}$ \\
\hline Ram reddy gudem & $\mathrm{S} 1$ & 7.09 & 1802 & 1.65 & 19 \\
\hline Bokkaloni pally & $\mathrm{S} 2$ & 7.11 & 1644 & 1.57 & 24 \\
\hline Zamistapur & $\mathrm{S} 3$ & 8.19 & 1641 & 1.91 & 17 \\
\hline Telugu gudem & $\mathrm{S} 4$ & 7.68 & 1412 & 1.34 & 26 \\
\hline Oblaipally & $\mathrm{S} 5$ & 7.78 & 1515 & 1.63 & 17 \\
\hline Machen pally & $\mathrm{S} 6$ & 7.59 & 2710 & 1.12 & 109 \\
\hline Nehru nagar & $\mathrm{S} 7$ & 7.2 & 612 & 1.16 & 40 \\
\hline Ram chandra puram & $\mathrm{S} 8$ & 7.82 & 709 & 1.24 & 27 \\
\hline Chowder pally & $\mathrm{S} 9$ & 7.12 & 1216 & 1.37 & 26 \\
\hline Appaipally & $\mathrm{S} 10$ & 7.89 & 1788 & 1.16 & 26 \\
\hline Narsapur & $\mathrm{S} 11$ & 7.35 & 1180 & 1.81 & 6 \\
\hline Dharmapur & $\mathrm{S} 12$ & 7.14 & 1574 & 1.62 & 8 \\
\hline Alipur & $\mathrm{S} 13$ & 7.19 & 2760 & 1.6 & 132 \\
\hline Kodur & $\mathrm{S} 14$ & 7.8 & 1775 & 1.13 & 24 \\
\hline Oblaipally Thanda & $\mathrm{S} 15$ & 7.8 & 1672 & 1.7 & 21 \\
\hline
\end{tabular}

\section{$3.1 \mathrm{pH}$}

The $\mathrm{pH}$ of water is a very important indication of its quality and provides important information in many types of geochemical equilibrium or solubility calculation (Hem, 1985).According to WHO standards $\mathrm{pH}$ of water should be 6.5 to 8.5 . In this study samples were found 7.09 to 8.19 which are slight basic. The highest $\mathrm{pH}$ value 8.19 observed at Zamistha pur station (S3) where as the lowest value i.e 7.09 found at Ram reddy gudem (S1). All the ground water samples found within the limits as prescribed by WHO. Higher alkalinity of groundwater activates leaching of fluoride and thus increases concentration of fluoride ions in groundwater (Wodeyar and Sreenivasan, 1996).

\subsection{Electrical Conductivity (EC)}

According to WHO standards EC value should not exceeded $400 \mu \mathrm{S} / \mathrm{cm}$. In study area all the ground water samples were found excess values of electrical conductivity. The value ranges from $612 \mu \mathrm{S} / \mathrm{cm}$ to $2760 \mu \mathrm{S} / \mathrm{cm}$. The highest EC found at Alipur (S13) i.e $2760 \mu \mathrm{S} / \mathrm{cm}$. Higher concentrations indicate the ionic concentrations are more in the groundwater. The conductivity measurement provides an indication of ionic concentration. It depends upon temperature, concentration and types of ions present (Hem, 1985). High conductance is attributed to high concentration of salts in groundwater (Davies and Dewiest, 1966).

\subsection{Fluoride (F)}

Fluorides may be presence due to breakdown of rocks and soils or infiltration of chemical fertilizers from agriculture land. The maximum allowed limit of fluoride according to WHO is $1.0 \mathrm{mg} / \mathrm{lit}$. All the ground water samples found excess in limits. The high concentration of fluoride in the study area poses a sign of water quality problem. The highest fluoride value $(1.91 \mathrm{mg} / \mathrm{lit}$.) recorded at Zamistapur (S3) station. It is observed that the people living in high fluoride concentration areas are suffering from mottled teethes and also knee joint pains especially in younger 


\section{International Journal of Science and Research (IJSR) \\ ISSN (Online): 2319-7064 \\ Index Copernicus Value (2013): 6.14 | Impact Factor (2014): 5.611}

people. Moreover, dental and skeletal fluorosis is at alarming stage in local resident of these areas.

\subsection{Nitrates $\left(\mathrm{NO}_{3}\right)$}

The WHO allows maximum permissible limit of nitrate in drinking water is $45 \mathrm{mg} / \mathrm{l}$. In study areas, results clear that the concentration of nitrate ranges from $6 \mathrm{mg} / \mathrm{lit}$. to $132 \mathrm{mg} / \mathrm{lit}$. Except Alipur(S13 found 132mg/lit) and Machen pally(S6 found $109 \mathrm{mg} / \mathrm{lit}$ ) remaining all samples were found within the limits. The high concentration of nitrate leads to blue baby syndrome in infants. The reason for high nitrate in groundwater is anthropogenic activities like the use of synthetic $\mathrm{N}$ fertilizers like urea, calcium ammonium nitrate, ammonium phosphate, ammonium sulphate is on the increase in the agricultural sector, which is the major source for nitrates in the groundwater.

\section{Conclusion}

Ground water samples chemical investigation carried out of selected villages of Mahabubnagar mandal and district slightly alkaline in nature. Nearly 33\% of ground water samples of study area shown electrical conductivity higher than the prescribed limit of $1500 \mu \mathrm{S} / \mathrm{cm}$ for drinking water. The higher values indicate ionic concentrations are more in ground water. $53 \%$ of ground water samples show excess fluoride prescribed for drinking purpose. It is observed that the people who are using ground water as drinking water are suffering from mottled teeth and also knee joint pains. 13\% of ground water samples found excess nitrates. The high concentration of nitrate leads to blue baby syndrome in infants. In connection with control of fluoride and nitrate, concerned government authorities should take initiative to establish advanced water treatment plants which focus on reducing of fluoride and nitrate concentration.

\section{References}

[1] Amra Bratovcic and Amra Odobasic, Determination of Fluoride and Chloride Contents in Drinking Water by Ion Selective Electrode, Journal of environmental Monitoring, 2011; 11(2): 109-120.

[2] M. B. RajkovićlandIvana D. Novakovići, Determination Of Fluoride Content In Drinking Water And Tea Infusions Using Fluoride Ion Selective Electrode, Journal of Agricultural Sciences, 2007; 2(52):155-168.

[3] World Health Organisation (WHO) 2002, Fluorides, World Health Organization (Environmental Health Criteria 227).

[4] Bell, M. C. and Ludwig, T.G. (1970): The Supply Of Fluoride To Man: Ingestion From Water, Fluorides And Human Health, WHO Monograph Series 59, World Health Organisation, Geneva.

[5] Gautam, R., Bhardwaj, N. And Saini, Y. (2011): Study of Fluoride Content in Groundwater of Nawa Tehsil in agaur, Rajasthan. J. Environmental Biology, 32 (1): 8589

[6] Sarala K. and P.R. Rao., 1993, Endemic fluorosis in the village Ralla Anantapuram in Andhra Pradesh: An Epidemiological Study, Fluoride, 26, pp 177-180.
[7] Jacks, G. et. al., 1993, Genesis of high F groundwater, Southern India, Applied geochemistry, Vol 2 , pp - 3.

[8] Ramesam V \& Rajagopalan K ,1985, Fluoride ingestion into the natural waters of hard- rock areas, Peninsular India, J Geol Soc India, 26, pp 125-132.

[9] N. J. Raju, S. Dey, K. Das, (2009). Fluoride contamination in ground waters of Sonbhadra district, Uttar Pradesh, India, Current Science, 96 (7): 979-985.

[10]S. Chouhan, S. J. S. Flora, (2010): Arsenic and Fluoride: Two Major Groundwater Pollutants, Indian Journal of Experimental Biology, 48: 666-678.

[11] Meenakshi Garg, V.K., Kavita, Renuka and Malik, A. (2004). Ground water quality in some villages of aryana, India: Focus on fluoride and fluorosis. J. Hazardous Materials 106: 85-97.

[12] Viswanathan G.R., (1935). Annual Report Madras. Indian Council of Agricultural Research, New Delhi. Quoted from Indian Institute of Science, 33A:1, 1951 